\title{
Chestnut wood extract in boar diet reduces intestinal skatole production, a boar taint compound
}

\author{
Diana Bilić-Šobot ${ }^{1}$ - Galia Zamaratskaia ${ }^{2}$ - Martin Krøyer Rasmussen ${ }^{3}$. \\ Marjeta Čandek-Potokar ${ }^{1,4}$ - Martin Škrlep ${ }^{4}$ Maja Prevolnik Povše ${ }^{1,4}$. \\ Dejan Škorjanc ${ }^{1}$
}

Accepted: 27 September 2016/Published online: 20 October 2016

(C) INRA and Springer-Verlag France 2016

\begin{abstract}
Abandoning traditional practice of piglet castration will impact the pigmeat sector. As a consequence, there is a need for research aiming at reducing boar taint caused by androstenone and skatole. Skatole is metabolized by cytochrome P450 enzymes (CYP450) in the liver. Skatole hepatic clearance is believed to be hindered by androstenone. Diet ingredients may modify skatole metabolism. Therefore, we tested the effect of hydrolysable tannins. We fed 51 young boars with 1-3\% chestnut wood extract as supplementary diet. After slaughter, the tissues were collected to assess androstenone and skatole accumulation in fat and to measure CYP450 activities, gene, and protein expression in the liver and intestine. Protein expression of two enzymes involved in androstenone metabolism, 3-beta-hydroxysteroid dehydrogenase $(3 \beta$-HSD) and sulfotransferase family $2 \mathrm{~A}$ member 1 (SULT2A1), was assessed, and feces collected to evaluate skatole production. Results show that intestinal skatole production in boars supplemented with $3 \%$ of chestnut wood extract was more than halved. The intestinal catalytic activities of CYP450 were tenfold lower than hepatic and were mainly unaffected by tannins. Findings indicate a potential effect of tannins on steroidogenesis, which in the absence of effect on
\end{abstract}

Marjeta Čandek-Potokar

meta.candek-potokar@kis.si

1 Faculty of Agriculture and Life Sciences, University of Maribor, Pivola 10, 2311 Hoče, Slovenia

2 Uppsala BioCenter, Department of Food Science, Swedish University of Agricultural Sciences, P.O. Box 7051, SE-750 07 Uppsala, Sweden

3 Department of Food Science, Aarhus University, Tjele, Denmark

4 Agricultural Institute of Slovenia, Hacquetova ulica 17, 1000 Ljubljana, Slovenia
$3 \beta$-HSD and SULT2A1 expression suggests lower synthesis of androstenone due to tannins.

Keywords Skatole $\cdot$ Androstenone $\cdot$ Cytochrome P450 . Tannins

\section{Introduction}

Sustainable food production systems are an essential part of a future agriculture and are in turn related to the welfare of animals, farmed for food purposes. Pork is one of the most widely consumed meat in the world. To improve sensory quality of pork, male piglets intended for meat industry are surgically castrated in many countries. Surgical castration minimizes an unpleasant off-flavor (boar taint) which otherwise can develop in meat when boars reach puberty and is generally disliked by the consumers. According to current trends (European declaration on alternatives to surgical castration of pigs), this practice has been recognized as animal welfare problem and is likely to be abandoned. Fattening boars may thus become a more widespread practice in the EU. However, to avoid consumer dissatisfaction, sustainable methods for minimizing boar taint levels in the meat need to be developed.

Skatole is one of two main compounds of boar taint. It is produced in the large intestine by bacterial degradation of amino acid $L$-tryptophan and after absorption is transported to the liver, where it is metabolized (Fig. 1). Hepatic CYP450-mediated metabolism is the major way by which pigs eliminate skatole (Zamaratskaia and Squires 2009). However, biotransformation of skatole might also occur in extra-hepatic tissues, such as the intestine. The CYP450 profile in the porcine large intestine has not yet been fully characterized. The presence of CYP3A activity in the pig colon was recently demonstrated, and this activity was induced by 
Fig. 1 Boar taint is a complex, unpleasant, sensory sensation of meat from entire male pigs which may develop after they reach sexual maturity. It has been ascribed to fat tissue accumulation of androstenone and skatole, two substances with interrelated metabolism. Nutrition has an important impact on boar taint compounds

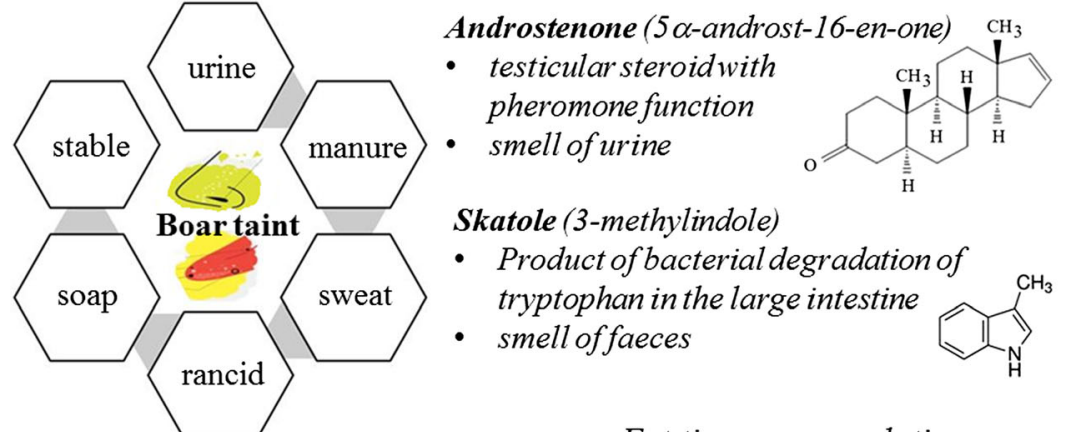

Fat tissue accumulation
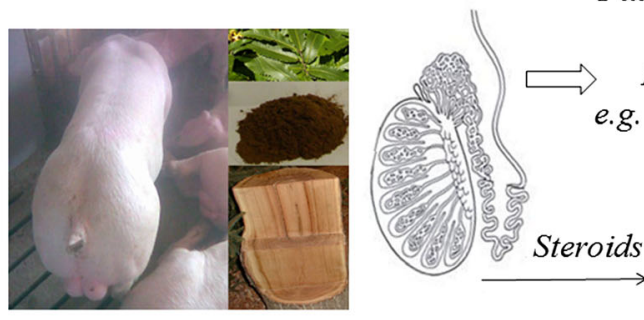

仓

Liver enzymes e.g. cytochrome $P 450$

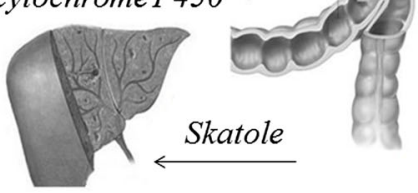

Hydrolysable tannins influence metabolism of boar taint compounds dietary hydrolysable tannins (Zamaratskaia et al. 2015). We hypothesized that higher activity of skatole-metabolizing enzymes in the colon might at least partly contribute to lower skatole intestinal absorption in adipose tissue. If the hepatic clearance of skatole is lower, excess skatole will be accumulated in the adipose tissue, giving rise to boar taint. The concentration of skatole in adipose tissue is therefore a result of multifaceted processes such as its formation, absorption, metabolism, and deposition Due to its intestinal origin, skatole concentrations are largely dependent on nutritional factors (Wesoly and Weiler 2012). Skatole is to a certain extent associated with androstenone - the second main compound of boar taint — because it is believed that androstenone together with other testicular steroids can inhibit skatole hepatic clearance (Rasmussen and Zamaratskaia 2014). Androstenone is produced in the testes similarly to anabolic hormones but has no known hormonal activity (Zamaratskaia and Squires 2009). Thus, androstenone is mainly affected by puberty stage and genetic background of the pigs (review of Bilić-Šobot et al. 2014). It is generally believed that dietary factors are less important in the regulation of androstenone levels.

Tannins are water-soluble polyphenols with varying molecular weights. They are chemically classified as hydrolysable or condensed tannins and are both considered to have either adverse or beneficial effects depending on their concentration and nature (Mennen et al. 2005). In many animal species, adding tannins in the diet showed negative effects including hepatotoxicity, toxic nephrosis, feed intake depression, and growth reduction as they reduce digestibility of proteins, lower the activity of digestive enzymes, cause damage to intestinal mucosa, or exert systemic toxic effects (MuellerHarvey 2006). On the other hand, tannins can also have positive health effects in animals such as antibacterial, antiparasitic, antioxidant, antidiarrheal, and anticancer properties (Mennen et al. 2005). Pigs from the Mediterranean region often consume relatively large amounts of acorns (containing 3-7 \% of tannins) during the fattening ("montanera") phase (Rodríguez-Estévez et al. 2011). This is an example of positive effects of tannins and can be explained by adaptation to high tannin levels through the proline-rich proteins (PRP) from saliva (tannin-binding salivary protein comprise PRP and histatins, the compounds with strong affinity for tannins; Mole et al. 1990). PRPs present the first evolutionary defense mechanism in animal species against the protein precipitating activity of tannins.

Tannins are known to have bitter or astringent taste which reduces palatability and consequently negatively affect pigs' voluntary feed intake and growth performance. It has also been shown that they inhibit specific gastric enzymes (Murakami et al. 1992), decrease small intestine proteolytic enzymes activity (van Leeuwen et al. 1995), decrease activity of trypsin in pancreatic tissue (catalyzes the hydrolysis of peptide bonds in duodenum), and activate brush border (glutamyl transferase). This could disturb absorption of nutrients in the small intestine in pig pancreas and brush border of small intestine (Lizardo et al. 1995), reduce protein digestibility (Smulikowska et al. 2001), and increase the excretion of endogenous proteins (Jansman et al. 1995). On the other hand, it has been shown that feeding weaned piglets with tannin wood extract can improve feed efficiency and reduce intestinal bacterial proteolytic reaction (Biagi et al. 2010), which results in reduced count of harmful and elevated count of beneficial microorganisms in feces and increased growth performance during pre-fattening and fattening period (Brus et al. 2013). Despite generally believed negative impact of tannins on growth performance, Lee et al. (2016) suggested that diet 
of pigs could be supplemented up to $5 \%$ with tannin-rich chestnut. A recent study by Čandek-Potokar et al. (2015) demonstrated no negative effects on growth performance in boars supplemented with 1 and $2 \%$ extract of hydrolysable tannins, induced activity of cytochrome CYP450, likewise potential positive effects on reduction of boar taint; however, further studies are needed to validate first results as well as elucidate underlying mechanisms.

The aim of present study was to evaluate the use of dietary hydrolysable tannins as an alternative to surgical castration of pigs, to prevent boar taint. Specifically, we investigated the effect of hydrolysable tannins on skatole levels at various sites and it effect on CYP450 (activities, gene, and protein expression). Moreover, the effect of dietary hydrolysable tannins on the levels of androstenone was also evaluated.

\section{Material and methods}

\subsection{Animals and experimental design}

The experiment was carried out on a commercial family farm in the eastern part of Slovenia respecting the Slovenian law on animal protection (Uradni list Republike Slovenije 43/2007). The experiment comprised 51 entire male pigs (boars), crossbreeds of Landrace and Large White. At approx. $55 \mathrm{~kg}$ of live weight (126 days of age), pigs were randomly assigned to four treatment groups (pens) and started receiving experimental diets ( 2 weeks of transition period to experimental diet only). For all treatment groups, commercial feeding mixture BEK-2 was used (produced by Jata Emona d.o.o., Ljubljana, Slovenia) with 12.9 MJ ME/kg and $15 \%$ of crude proteins (detailed information is given in Zamaratskaia et al. 2015). Pigs were fed according to feeding plan respecting requirements of pigs during fattening period (in average $2.9 \mathrm{~kg}$ per pig daily). The feed mixture for control group (T0, $n=12$ ) had no tannin supplementation, whereas the other three mixtures (for T1, T2, and T3 groups) were supplemented with 1, 2, and $3 \%$ tannin extract Farmatan® (Tanin Sevnica d.d., Sevnica, Slovenia), respectively. The estimate of the quantity of consumed tannins per day is presented in Table 1. The experiment lasted 77 days and was finished when pigs had approx. 205 days of age. Pigs were slaughtered according to the standard abattoir procedure. After the removal of the digestive tract, the intestinal content, intestinal mucosa (colon descendens), and liver were sampled, immediately frozen in liquid nitrogen and stored at $-80{ }^{\circ} \mathrm{C}$ until further analyses. At the end of slaughter line, subcutaneous fat samples were taken for the subsequent determinations of androstenone and skatole concentration. At the slaughter line, testes were removed and weighed.

\subsection{Zootechnical performance}

Boars were weighed at the beginning (at $53.0 \pm 5.3 \mathrm{~kg}$ live weight) and at the end of experiment (at $126.7 \pm 11.3 \mathrm{~kg}$ live weight) which lasted 77 days. Daily gain (individual) was calculated based on these two measurements and represents growth rate (g/day) for the experimental period. The feeding was monitored, and the same quantity of feed was offered daily to all pigs.

\subsection{Intestinal content analyses}

Intestinal $\mathrm{pH}$ measurements were performed in a supernatant ( $1 \mathrm{~g}$ of sample was diluted in $4 \mathrm{~mL}$ of water, vortexed for $20 \mathrm{~s}$, and centrifuged at $3000 \mathrm{~g}$ for $15 \mathrm{~min}$ ) using MP120 pH meter (Mettler-Toledo). Determination of intestinal dry matter (DM) and ammonia nitrogen content was measured as described in Čandek-Potokar et al. (2015). Shortly, samples for DM determination were dried in vacuum oven (SP-105C, Kambič) and weighed. Concentration of ammonia nitrogen was determined with Kjeldahl digestion. Ammonia titration was performed using $0.15 \mathrm{M}$ hydrochloric acid and measured with Tecator 2020 Digestor apparatus (Foss Tecator) for the digestion.

Skatole and indole concentration of intestinal content was measured according to the modified method described in Čandek-Potokar et al. (2015). Samples (5 g) were suspended in $20 \mathrm{~mL}$ of methanol, homogenized, centrifuged, and internal standard (2-methylindole) was added. Tris buffer was added, and the mixture was cleaned on a Supelclean LC-18 SPE column (Supelco). Using high-performance liquid chromatography (HPLC; HP 1200, Agilent Technologies, Waldbronn, Germany) equipped with a fluorescence detector $(\lambda \mathrm{ex}=285 \mathrm{~nm}, \lambda \mathrm{em}=340 \mathrm{~nm})$ separation and quantification of skatole and indole contents was performed.

\subsection{Skatole and androstenone concentration in subcutaneous fat}

The concentration of boar taint compounds was determined using HPLC (HP 1200, Agilent Technologies, Waldbronn, Germany) equipped with a fluorescence detector according to the procedure described in Pauly et al. (2008). Shortly, samples (10-20 g) were liquefied in microwave oven, then centrifuged at 11,200 $\mathrm{g}$ for $20 \mathrm{~min}$ at room temperature $\left(20^{\circ} \mathrm{C}\right)$. Centrifuged samples were heated to $50{ }^{\circ} \mathrm{C}$ and transferred in $2 \mathrm{~mL}$ Eppendorf tubes with different standards (androstanone and 2-methylindole in methanol). The next step included incubation and centrifugation. The mixture (10 or $20 \mu \mathrm{L}$, for androstenone or skatole determination, respectively) was injected into a HPLC column and fluorescence was detected (at $\lambda \mathrm{ex}=346 \mathrm{~nm}, \lambda \mathrm{em}=521 \mathrm{~nm}$ for androstenone and $\lambda$ ex $=285 \mathrm{~nm}, \lambda \mathrm{em}=340 \mathrm{~nm}$ for skatole). For androstenone, prior to injecting into HPLC column, 
Table 1 Zootechnical data and the effect of treatment group (T1-1\% tannin extract added; T2-2 \% tannin extract added; T3-3\% tannin extract added) on testes, boar taint compounds, and chemical traits of intestinal content (colon descendens). Intake of tannins (determined as gallic acid equivalents) was estimated taking into account their concentration in feed mixtures $(2.7,3.0,5.4,8.1 \mathrm{~g} / \mathrm{kg}$ for control, T1, T2, T3, respectively) and feed allowance of $2.9 \mathrm{~kg} / \mathrm{pig} / \mathrm{day}$. Mean values within a row with different superscripts significantly differ $(P<0.05) . P$ values given in brackets stand for log transformed values of androstenone or skatole

\begin{tabular}{|c|c|c|c|c|c|c|}
\hline \multirow[b]{2}{*}{ Number of pigs } & \multicolumn{4}{|c|}{ Treatment group } & \multirow[t]{2}{*}{$P$ value } & \multirow[t]{2}{*}{ RMS } \\
\hline & $\begin{array}{l}\text { Control } \\
12\end{array}$ & $\begin{array}{l}\mathrm{T} 1 \\
13\end{array}$ & $\begin{array}{l}\mathrm{T} 2 \\
13\end{array}$ & $\begin{array}{l}\mathrm{T} 3 \\
13\end{array}$ & & \\
\hline \multicolumn{7}{|l|}{ Zootechnical data } \\
\hline Initial live weight, $\mathrm{kg}$ & 56.3 & 52.5 & 49.7 & 53.7 & / & / \\
\hline Final live weight, $\mathrm{kg}$ & 117.9 & 125.3 & 129.9 & 133.2 & l & / \\
\hline Daily gain, kg & 800 & 945 & 1041 & 1032 & l & l \\
\hline Intake of tannins, g/pig/day & 7.8 & 8.8 & 15.8 & 23.5 & l & 1 \\
\hline Testes weight, $\mathrm{g}$ & 898 & 974 & 958 & 948 & 0.7671 & 0.18 \\
\hline Testes weight at equal live weight, $g$ & 1012 & 991 & 918 & 865 & 0.0850 & 0.14 \\
\hline \multicolumn{7}{|l|}{ Boar taint compounds } \\
\hline Androstenone, $\mu \mathrm{g} / \mathrm{g}$ fat & $0.33^{\mathrm{a}}$ & $0.85^{\mathrm{b}}$ & $0.75^{\mathrm{b}}$ & $0.40^{\mathrm{a}}$ & $0.0514(0.0030)$ & 0.55 \\
\hline Skatole, $\mu \mathrm{g} / \mathrm{g}$ fat & 0.16 & 0.15 & 0.22 & 0.15 & $0.2444(0.2085)$ & 0.11 \\
\hline \multicolumn{7}{|l|}{ Intestinal content chemical traits } \\
\hline $\mathrm{pH}$ & 7.48 & 7.31 & 7.28 & 7.39 & 0.1405 & 0.22 \\
\hline Dry matter, $\mathrm{mg} / \mathrm{g}$ & 248 & 226 & 220 & 204 & 0.2174 & 52.5 \\
\hline Indole, $\mu \mathrm{g} / \mathrm{g}$ & 3.06 & 3.52 & 3.16 & 3.50 & 0.7288 & 1.27 \\
\hline Indole, $\mu \mathrm{g} / \mathrm{g}$ dry matter & 12.5 & 15.8 & 15.2 & 18.1 & 0.1526 & 5.99 \\
\hline Skatole, $\mu \mathrm{g} / \mathrm{g}$ & $10.5^{\mathrm{a}}$ & $8.5^{\mathrm{a}}$ & $8.0^{\mathrm{ab}}$ & $4.8^{\mathrm{b}}$ & 0.0004 & 3.10 \\
\hline Skatole, $\mu \mathrm{g} / \mathrm{g}$ dry matter & $41.6^{\mathrm{a}}$ & $37.1^{\mathrm{a}}$ & $34.8^{\mathrm{a}}$ & $23.6^{\mathrm{b}}$ & 0.0004 & 10.1 \\
\hline Nitrogen, mg/g & 7.8 & 8.0 & 8.7 & 8.6 & 0.3425 & 1.56 \\
\hline Nitrogen, $\mathrm{mg} / \mathrm{g}$ dry matter & $31.5^{\mathrm{a}}$ & $35.9^{\mathrm{ab}}$ & $44.6^{\mathrm{b}}$ & $42.7^{\mathrm{b}}$ & 0.0018 & 8.84 \\
\hline $\mathrm{NH}_{3}, \mathrm{mg} / \mathrm{g}$ & $0.43^{\mathrm{a}}$ & $0.33^{\mathrm{b}}$ & $0.36^{\mathrm{ab}}$ & $0.35^{\mathrm{ab}}$ & 0.0140 & 0.08 \\
\hline $\mathrm{NH}_{3}, \mathrm{mg} / \mathrm{g}$ dry matter & 1.73 & 1.47 & 1.83 & 1.78 & 0.1955 & 0.45 \\
\hline
\end{tabular}

supernatant $(50 \mu \mathrm{L})$ was submitted to derivatization with dansyl hydrazine. Detection limit of methods was $0.24 \mathrm{mg} / \mathrm{g}$ for androstenone and $0.03 \mathrm{mg} / \mathrm{g}$ for skatole. Inter- and intraassay variation did not exceed $10 \%$.

\subsection{Catalytic activities of CYP1A1/2, CYP1A2, CYP2A19, CYP3A, and CYP2E1 in the liver and intestine}

Hepatic and intestinal microsomes were prepared using the calcium aggregation method (Rasmussen et al. 2011). Microsomal protein was determined using a commercially available kit (Bio-Rad Laboratories) according to the manufacturer's instructions. Catalytic activities of major enzymes involved in skatole metabolism CYP1A1/2, CYP1A2, CYP2A19, CYP3A, and CYP2E1 in the microsomes were measured. The activities of CYP1A1 and CYP1A2 were determined as the rates of 7-ethoxyresorufin O-deethylation and 7-methoxyresorufin O-demethylation, respectively, and the activities of CYP2A19 and CYP2E1 as the rates of coumarin and p-nitrophenol hydroxylation, respectively (Zamaratskaia et al. 2009). The activity of CYP3A was determined as the rate of 7-benzyloxyresorufin O-debenzylation (Zlabek and Zamaratskaia 2012). Product formation from corresponding substrate was linear as a function of the incubation time and of the protein content in the microsomes.
The reactions were started by the addition of 0.5 or $1 \mathrm{mM}$ NADPH and were conducted at $37^{\circ} \mathrm{C}$. All assays were performed in duplicate. The amount of formed metabolites was measured in duplicate on an HPLC system consisting of a pump (L-7100), autosampler (L-7200), fluorescence (L-7485), and UV-Vis detector (L-4250) and D-7000 HPLC Manager software (Merck Hitachi). Enzyme activity data were expressed as picomole metabolite formed per milligram protein/min.

\subsection{Gene expression}

Total RNA was isolated using Tri-reagent according to the manufacturer's instruction (Sigma-Aldrich), followed by the reverse transcription of $500 \mathrm{ng}$ RNA using the iScript complementary DNA (cDNA) synthesis Kit (Bio-Rad). The specific messenger RNA (mRNA) concentration was determined by real-time PCR using specific primers and TaqMan probes applied to equal amounts of cDNA from each sample. The reactions was performed in duplicates in 96-well plates under the following conditions: $50{ }^{\circ} \mathrm{C}$ for $2 \mathrm{~min}, 95{ }^{\circ} \mathrm{C}$ for $10 \mathrm{~min}$ followed by 40 cycles of $95^{\circ} \mathrm{C}$ for $15 \mathrm{~s}$, and $60{ }^{\circ} \mathrm{C}$ for $1 \mathrm{~min}$. The used primers and TaqMan probes for PCR were as follows: 


\begin{tabular}{llll}
\hline Target & Forward $\left(5^{\prime}-3^{\prime}\right)$ & Reverse $\left(5^{\prime}-3^{\prime}\right)$ & Probe $\left(5^{\prime}-3^{\prime}\right)$ \\
$1 A 1$ & TCCAGGATACTGGCACAAGGT & TCCTGCCTGCAAAGAGGAA & CCCGCTTAAACAAGGATGAGCAACCA \\
$2 A 19$ & TGGATGAGAACGGGCAGTT & AGAGCTCCATTCTAGCCAGACCTT & TCTCCATCGGAAAGCGGTACTGTTTCG \\
$2 E 1$ & CGGAAAGTTCAAGTACAGTGATCATT & GGCCCTCTCCGACACACA & CAAGGCATTTCCGCAGGAAAGCG \\
$3 A 29$ & GGACACCATAAATCCTTACACTTACCT & GCAAACCTCATGCCAATGC & CCTTTGGGACTGGACCCCGCAA \\
$3 \beta-H S D$ & GGGCGAGAGACCGTCATG & ACGCTGGCCTGGACACA & AGGTCAATGTGAAAGGTACCCAGCTC \\
SULT2Al & TTCCAGGAGAAGATGGCAGATC & AGGATTGGGAAGTTTGTGAACATT & TCCTCAAGAGCTGTTCCCATGGCAA \\
B-actin & ACCCAGATCATGTTCGAGACCTT & TCACCGGAGTCCATCACGAT & CTGTATGCCTCTGGCCGCACCA \\
\hline
\end{tabular}

The obtained Ct-values were normalized to expression of $\beta$-actin

\subsection{Western blotting}

Western blotting was performed using the microsomal fraction prepared as described in section 2.5. Equal amounts of protein $(20 \mu \mathrm{g})$ were separated on gels (any Kd, Bio-Rad) and electroblotted on to a polyvinylidene fluoride membrane. Following, staining with Ponceau S for visual inspection of blotting equality and efficiency, the membrane was blocked in trisbuffered saline with Tween 20 (TBST)-buffer ( $50 \mu \mathrm{M}$ Tris, $500 \mu \mathrm{M} \mathrm{NaCl}, 0.1 \%$ Tween $20 ; \mathrm{pH} 7.4$ ) added $2 \%$ dry milk. The membrane was incubated overnight with primary antibodies diluted in TBST-buffer containing $2 \%$ dry milk. After incubation with horseradish peroxidase-conjugated secondary antibodies, the membranes were washed several times in TBST-buffer before visualizing of the specific proteins with ECL substrate (Bio-Rad) and a CDD camera.

The used antibodies were all used in a concentration of 1:1000, CYP1A (Sc-53241, Santa Cruz), CYP2A (Sc53615, Santa Cruz), CYP2E1 (Ab28146, Abcam), CYP3A (Sc-25845, Santa Cruz), and 3 $\beta$-HSD (R1484, donated by J. Ian Mason, The University of Edinburgh, Scotland, UK).

\subsection{Statistical analysis}

Statistical analysis was carried out using GLM procedure of SAS (SAS Inc. Cary, USA) with fixed effect of treatment group (tannin addition). In the case of testes weight, final live weight was added in the model as covariate (it was significant at $P<0.001)$. When the effect of treatment group was significant $(P<0.05)$, multiple comparison of least squares means ( $L S$ means) was performed using Tukey test.

\section{Results and discussion}

\subsection{Catalytic activities of hepatic and intestinal CYP450}

Significant effect of tannin supplementation on the activities of hepatic CYP450 (Table 1) was observed only for CYP2E1 where T1 group had significantly (2.1-fold) lower values compared to $\mathrm{T} 2$ and $\mathrm{T} 3$. A trend of reduction was observed also for the activities of CYP1A1 and CYP2A19 $(P=0.10$ and $P=0.11$, respectively). In both cases, catalytic activities were progressively reduced with increasing tannin supplementation. In the intestine, only CYP1A and CYP3A showed activities. The intestinal activities were up to tenfold lower compared to the hepatic activities of the same enzymes. CYP3A activity was not affected by the including of tannins into the diet, whereas the activity of CYP1A was higher in the pigs supplemented with tannins.

\subsection{Gene expression in hepatic and intestinal tissue}

For all investigated genes (important for skatole metabolism), we found no differences in their expression in the liver between the experimental groups (Fig. 2). In the intestine, no consistent expression of CYP2E1 and 3 $\beta$-HSD was detected, meaning that $\mathrm{Ct}$-values for individual samples were below 35 or in most cases "non-detected." For intestinal CYP1A1, CYP2A19, and SULT1A2 expression, there were no differences between the experimental groups (Fig. 2).

\subsection{Protein expression in hepatic and intestinal tissue}

Protein expression of CYP1A, CYP2E1, CYP2A, and $3 \beta-$ HSD in the liver was not different between the experimental groups (Fig. 2). In the present study, a decrease in the hepatic CYP2E1 was not accompanied by a similar decrease in protein and gene expression indicating that CYP2E1 is regulated by post-transcriptional factors, such as stabilization of the enzyme. Discordant relationship between gene and protein expression and CYP2E1 activity is commonly observed in pigs and other species (Kocarek et al. 2000; Brunius et al. 2012).

The protein expression of CYP3A has been previously reported (Zamaratskaia et al. 2015). We detected no protein expression of CYP1A, CYP2E1, CYP2A, and $3 \beta$-HSD in the intestinal microsomes. 


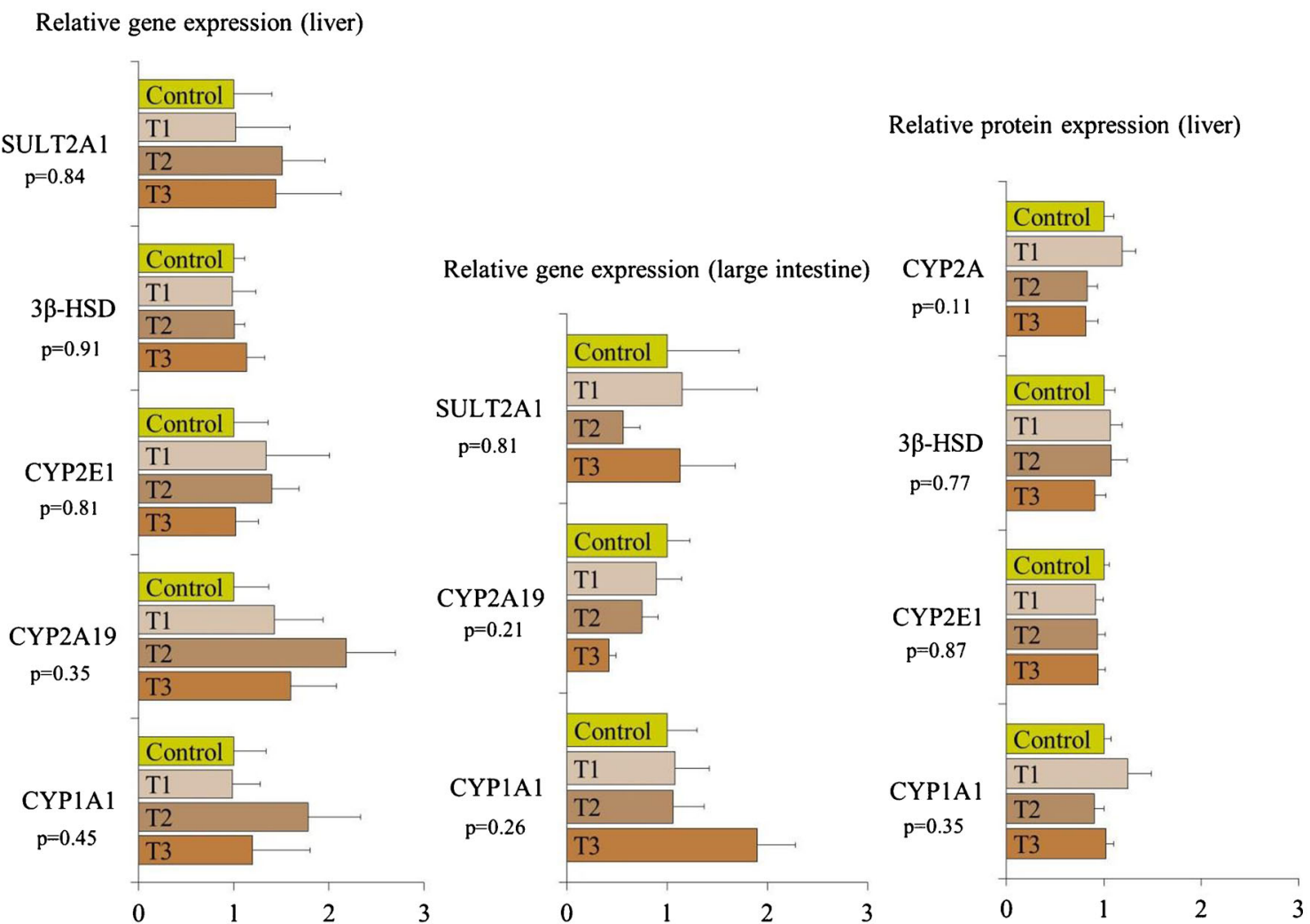

Fig. 2 Relative gene expression of all investigated enzymes was higher in the liver than in the large intestine. No significant effect of tannin extract supplementation (control-0\%; T1-1\%; T2-2\%; T3-3\%) was observed on relative gene expression either in the liver or large intestine. Likewise, protein expression of investigated enzymes in the liver did not differ between experimental groups. No protein expression was detected in the intestinal microsomes

by lower intestinal skatole levels (intestinal formation). CYP1A1/2 protein expression was not observed in the intestine. The study by Matal et al. (2009) indicated an involvement of CYP1A2 in skatole metabolism in the liver. It is not known if skatole is metabolized in the large intestine. Moreover, from our data, it is not possible to conclude if lower skatole levels in the intestinal content of pigs supplemented with tannins are due to reduced biosynthesis or to increased intestinal metabolism of skatole. In the future studies, it would be desirable to include measurements of skatole metabolites in the feces.

Unexpectedly, neither CYP2E1 nor CYP2A19 expression and activities in the liver were affected by dietary hydrolysable tannins. CYP2E1 activity was the highest in T2 and T3 groups which had two- and threefold higher intake of tannins as control or $\mathrm{T} 1$; however, the difference was significant only in comparison to $\mathrm{T} 1$ and not to control group. Limited knowledge exists regarding regulation of CYP450 by dietary tannins, and the results are controversial. Intraperitoneal treatment of female Swiss mice with tannic acid in the dose range of $20-80 \mathrm{mg} / \mathrm{kg}$ resulted in reduction of hepatic EROD and MROD activities by 25-28\%, and PNPH by $50 \%$ (KrajkaKuźniak and Baer-Dubowska 2003). In Sencas mice, EROD activity was also reduced in the lung and forestomach after 
tannic acid supplementation (1\%) (Athar et al. 1989). Tannic acid inhibited CYP2E1 activity in the liver microsomes from acetone-induced mice (Mikstacka et al. 2002). The exact mechanism of CYP450 regulation by hydrolysable tannins is yet to be elucidated.

As the results on androstenone (Table 2) indicate the effect of tannins on sexual development, corresponding differences in $3 \beta$-HSD and SULT2A1 expression could be expected. However, this was not the case. This fact could suggest that experimental diet was not increasing the hepatic metabolism of androstenone, but is indicative of its lower synthesis. Despite numerous health benefits, adverse effects of polyphenolic compounds with excessive consumption have also been reported among which reduced fertility in animals and sexual maturity in infants, antiandrogenic effects, and testicular atrophy in rats (Mennen et al. 2005).

\subsection{Zootechnical performance, testes weight, boar taint compounds, and intestinal content}

Zootechnical performance of fattening boars (Table 2) was monitored, and there was no adverse effect of tannin addition, even at relatively high levels. Final body weight (and growth rate) was lower in control group of pigs in spite of the same daily ratio offered (per pig). Growth rate was not affected by tannins, contrary to our first study, in which fattening boars were individually housed, and reduced feed intake (and consequently growth rate) was noted at $3 \%$ tannin inclusion (Čandek-Potokar et al. 2015). Another point of relevance is the final concentration of tannins in the feed mixture. Our aim was to supplement the basic diet with 1,2 , and $3 \%$ of tannin extract, but the posterior chemical analysis of feed mixtures showed that the actual concentrations of total phenolic compounds were similar in control and T1 group denoting similar intake of tannins which should be taken into account when interpreting results on CYP450.

It has been demonstrated in growing boars that testes/body volume ratio increases with body weight and can be used to identify boars with high androstenone level (Font i Furnols et al. 2016). In the present study, the effect of treatment group was not significant on testes weight (Table 2), however, adding final body weight in the model as covariate (i.e., comparison at the same weight) indicated a tendency $(P=0.0850)$ of smaller testes with increasing tannin supplementation. This result is further corroborated with the effect on androstenone where we could note a progressive decrease of androstenone level with increasing tannin supplementation (from $0.85 \mu \mathrm{g} / \mathrm{g}$ in T1 to $0.40 \mu \mathrm{g} / \mathrm{g}$ in T3, $P=0.05)$. Similar extent of androstenone reduction was also observed in our first study (Čandek-Potokar et al. 2015) though statistically insignificant. Low level of androstenone in control group could be explained by its correlation with testes weight $(r=0.67$ reported by Aldal et al. 2005). For what regards the androstenone and skatole deposited in fat, the first was comparable whereas the later was generally higher as in the first study (we used same crossbreed and origin of pigs). Contrary to our first study, we could not find any effect of tannin supplementation on skatole deposited in fat. The effect of dietary supplements on the concentration of androstenone in adipose tissue is less known except for studies of Rasmussen et al. (2012). In this study, chicory root as dietary supplement was found to be related to higher expression of the enzyme $3 \beta$ HSD, which is essential for hepatic metabolism as it catalyzes the transformation of androstenone to $\beta$-androstenol. The correlations between adipose tissue skatole concentration and CYP450 activities, gene, and protein expression were mainly weak and non-significant except with the liver CYP2E1 activity $(r=0.36)$ and intestinal CYP3A activity $(r=0.33)$.

The effect of tannin supplementation on $\mathrm{pH}$, dry matter, indole, and skatole concentrations of intestinal content in colon descendens was the most pronounced on skatole concentration (in fresh and dry matter). Despite constant reduction of skatole concentration from control to T3, only T3 group differed significantly from other three groups and was reduced by half compared to control group. Significant effect of tannin supplementation could also be observed on nitrogen content
Table 2 Catalytic activities ( $\mathrm{pmol} / \mathrm{mg}$ protein $/ \mathrm{min}$ ) of cytochrome 450 (CYP450) enzymes in the liver and large intestine (colon descendens) according to treatment group (T1-1\% tannin extract added; T2-2 \% tannin extract added; T3-3 $\%$ tannin extract added). $P$ values given in brackets stand for $\log$ transformed values of catalytic activity

\begin{tabular}{lllllll}
\hline & $\begin{array}{l}\text { Control } \\
\text { Number of pigs }\end{array}$ & $\begin{array}{l}\text { T1 } \\
12\end{array}$ & $\begin{array}{l}\text { T2 } \\
13\end{array}$ & $\begin{array}{l}\text { T3 } \\
13\end{array}$ & $P$ value & RMSE \\
\hline Liver & & & & & & \\
CYP1A1/2 (EROD) & 16.85 & 15.23 & 10.11 & 12.86 & $0.3533(0.5000)$ & 9.88 \\
CYP1A1 (MROD) & 3.87 & 2.49 & 2.21 & 1.99 & $0.0988(0.5109)$ & 1.99 \\
CYP2E1 (PNPH) & $95.2^{\mathrm{ab}}$ & $52.2^{\mathrm{a}}$ & $108.9^{\mathrm{b}}$ & $112.1^{\mathrm{b}}$ & $0.0056(<0.0001)$ & 45.7 \\
CYP2A19 (COH) & 83.0 & 52.4 & 48.8 & 37.3 & $0.1156(0.5827)$ & 47.5 \\
CYP3A (BROD) & 7.62 & 6.12 & 7.16 & 6.55 & $0.8909(0.8722)$ & 5.17 \\
Large intestine & & & & & & $0.0313(0.0204)$ \\
CYP1A1/2 (EROD) & $1.27^{\mathrm{a}}$ & $1.48^{\mathrm{ab}}$ & $1.78^{\mathrm{b}}$ & $1.77^{\mathrm{b}}$ & 0.49 \\
CYP3A (BROD) & 0.83 & 1.11 & 1.06 & 0.96 & $0.3162(0.3397)$ & 0.40 \\
\hline
\end{tabular}

${ }^{\mathrm{a}, \mathrm{b}}$ LSmeans assigned different supescript letter are significantly different $(P<0.05)$ 
in DM, as it was significantly higher in T2 and T3 than control group. Similar trend, although not significant, could be noted for nitrogen content of wet matter. Ammonia content was reduced with tannin supplementation, but the difference was significant only between control and T1. No effect of tannin supplementation was observed on $\mathrm{pH}$ and indole content. In agreement with our previous study (Čandek-Potokar et al. 2015), we observed a clear effect of tannin supplementation on (reduced) skatole production in the intestine, which indicates a beneficial effect on gut ecology. We also confirmed the increase of $\mathrm{N}$ concentration in the intestinal content due to adding the tannins, indicating their ability to complex proteins.

\section{Conclusion}

Intestinal catalytic activities of CYP450 were tenfold lower than hepatic and were mainly unaffected by tannins. General trend was reduced catalytic activities of CYP450 in hepatic microsomes, however significantly only CYP2E1 of T1. There was also no difference in gene or protein expressions of studied CYP450 either in the liver or in the intestine (mostly non-detected). Results on androstenone indicate effect of tannins on sexual development, which along with absence of effect on $3 \beta$-HSD and SULT2A1 expression suggests its lower synthesis. Overall, hydrolysable tannins might exert potential for boar taint prevention via reduced intestinal skatole production and antiandrogen impacts.

Acknowledgments The authors would like to thank for the financial support of Slovenian Research Agency (grant P1-0164, P4-0133 for core financing and project grant L4-5521). Co-financing of the Slovenian Ministry of agriculture, forestry, and food is also acknowledged. Diana Bilić-Šobot was supported by a doctoral fellowship from ERASMUS MUNDUS Action 2 - Strand 1 - Lot 6 Project JoinEU-SEE IV.

\section{References}

Aldal I, Andresenb Egeli AK, Haugen J-E, Grødum A, Fjetlande O, Eikaas JLH (2005) Levels of androstenone and skatole and the occurrence of boar taint in fat from young boars. Livest Prod Sci 95: 121-129. doi:10.1016/j.livprodsci.2004.12.010

Athar M, Khan WA, Mukhtar H (1989) Effect of dietary tannic acid on epidermal lung, and forestomach polycyclic aromatic hydrocarbon metabolism and tumorigenicity in Sencar mice. Cancer Res 49: 5784-5795

Biagi G, Cipollini I, Paulicks BR, Roth FX (2010) Effect of tannins on growth performance and intestinal ecosystem in weaned piglets. Arch Anim Nutr 64:121-135. doi:10.1080/17450390903461584

Bilić-Šobot D, Čandek-Potokar M, Kubale V, Škorjanc D (2014) Boar taint: interfering factors and possible ways to reduce it. Agricultura 11(1/2):35-48

Brunius C, Rasmussen MK, Ekstrand B, Lacoutiere H, Andersson K, Zamaratskaia G (2012) Expression and activities of hepatic cytochrome P450 (CYP1A, CYP2A and CYP2E1) in entire and castrated male pigs. Animal 6(2):271-277. doi:10.1017 /S1751731111001674

Brus M, Dolinšek J, Cencič A, Škorjanc D (2013) Effect of chestnut (Castanea sativa Mill.) wood tannins and organic acids on growth performance and faecal microbiota of pigs from 23 to 127 days of age. Bulg J Agric Sci 19(4):841-847

Čandek-Potokar M, Škrlep M, Batorek Lukač N, Zamaratskaia G, Prevolnik Povše M, Velikonja Bolta Š, Kubale V, Bee G (2015) Hydrolysable tannin fed to entire males affects intestinal production, tissue deposition and hepatic clearance of skatole. Vet J 204:162167. doi:10.1016/j.tvj1.2015.02.012

Font i Furnols M, Carabus A, Munoz I, Čandek-Potokar M, Gispert M (2016) Evolution of testes characteristics in entire and immunocastrated male pigs from 30 to $120 \mathrm{~kg}$ live weight as assessed by computed tomopgraphy with perspective on boar taint. Meat Sci 116:8-15. doi:10.1016/j.meatsci.2016.01.008

Jansman AJM, Verstegen MWA, Huisman J, van der Berg JWO (1995) Effects of hulls of faba beans (Vicia faba L.) with a low or high content of condensed tannins on the apparent ileal and fecal digestibility of nutrients and the excretion of endogenous protein in ileal digesta and feces in pigs. J Anim Sci 73:118-127

Kocarek TA, Zangar RC, Novak RF (2000) Post-transcriptional regulation of rat CYP2E1 expression : role of CYP2E1 mRNA untranslated regions in control of translational efficiency and message stability. Arch Biochem Biophys 376(1):180-190. doi:10.1006/ abbi.2000.1704

Krajka-Kuźniak V, Baer-Dubowska W (2003) The effects of tannic acid on cytochrome P450 and phase II enzymes in mouse liver and kidney. Toxicol Lett 143(2):209-216. doi:10.1016/S0378-4274(03) 00177-2

Lee HJ, Choi IH, Kim DH, Amanullah SM, Kim SC (2016) Nutritional characterization of tannin rich chestnut (Castanea) and its meal for pig. J Appl Anim Res 44(1):258-262. doi:10.1080/09712119.2015.1031779

Lizardo R, Peiniau J, Aumaitre A (1995) Effect of sorghum on performance, digestibility of dietary components and activities of pancreatic and intestinal enzymes in the weaned piglet. Anim Feed Sci Technol 56:67-82. doi:10.1016/0377-8401(95)00813-3

Matal J, Matusokova Z, Tunkova A, Anzenbacherova E, Anzenbacher P (2009) Porcine CYP2A19, CYP2E1 and CYP1A2 forms are responsible for skatole biotransformation in the reconstituted system. Neuroendocrinol Lett 30:36-40

Mennen LI, Walker R, Bennetau-Pellisero C, Scalbert A (2005) Risks and safety of polyphenol consumption ${ }^{1-3}$. Am J Clin Nutr 81(suppl): 326S-329S

Mikstacka R, Gnojkowski J, Baer-Dubowska W (2002) Effect of natural phenols on the catalytic activity of cytochrome P450 2E1. Acta Biochim Pol 49(4):917-925

Mole S, Butler LG, Iason G (1990) Defence against dietary tannins in herbivores: a survey for proline-rich salivary proteins in mammals. Biochem Syst Ecol 18:287-293. doi:10.1016/0305-1978 (90)90073-O

Mueller-Harvey I (2006) Unravelling the conundrum of tannins in animal nutrition and health. J Sci Food Agric 86:2010-2037. doi:10.1002/ jsfa. 2577

Murakami S, Muramatsu M, Otomo S (1992) Inhibitory effect of tannicacids on gastric $\mathrm{H}^{+}, \mathrm{K}^{+}$-ATPase. J Nat Prod 55:513-516. doi: $10.1021 / n p 50082 \mathrm{a} 022$

Pauly C, Spring P, O’Doherty JV, Ampuero Kragten S, Bee G (2008) Performances, meat quality and boar taint of castrates and entire male pigs fed a standard and a raw potato starch-enriched diet. Animal 2:1707-1715. doi:10.1017/S1751731108002826

Rasmussen MK, Zamaratskaia G (2014) Regulation of porcine hepatic cytochrome p450-implication for boar taint. Comput Struct Biotechnol J 11:106-112. doi:10.1016/j.csbj.2014.09.003 
Rasmussen M, Ekstrand B, Zamaratskaia G (2011) Comparison of cytochrome $\mathrm{P} 450$ concentrations and metabolic activities in porcine hepatic microsomes prepared with two different methods. Toxicology in Vitro 25: 343-346. doi:10.1016/j.tiv.2010.10.007

Rasmussen MK, Brunius C, Zamaratskaia G, Ekstrand B (2012) Feeding dried chicory root to pigs decreases androstenone accumulation in fat by increasing hepatic $3 \beta$ hydroxysteroid dehydrogenase expression. J Steroid Biochem 130:90-95. doi:10.1016/j.jsbmb.2012.01.003

Rodríguez-Estévez V, Sánchez- Rodríguez M, García AR, Gómez-Castro AG (2011) Average daily weight gain of Iberian fattening pigs when grazing natural resources. Livest Sci 137:292-295. doi:10.1016/j. livsci.2010.11.015

Smulikowska S, Pastuszewska B, Święch E, Ochtabińska A, Mieczkowska A, Nguyen VC, Buraczewska L (2001) Tannin content affects negatively nutritive values of pea for monogastrics. J Anim Feed Sci 10:511-523

van Leeuwen P, Jansman AJ, Wiebenga J, Koninkx JF, Mouwen JM (1995) Dietary effects of faba-bean (Vicia faba L.) tannins on the morphology and function of the small-intestinal mucosa of weaned pigs. Br J Nutr 73(1):31-39. doi:10.1079/BJN19950006

Wesoly R, Weiler U (2012) Nutritional influences on skatole formation and skatole metabolism in the pig. Animals 2:221-242. doi:10.3390/ ani2020221

Zamaratskaia G, Squires EJ (2009) Biochemical, nutritional and genetic effects on boar taint in entire male pigs. Animal 3(11):1508-1521. doi:10.1017/S1751731108003674

Zamaratskaia, G., Zlabek, V., Chen, G., Madej, A., 2009. Modulation of porcine cytochrome P450 enzyme activities by surgical castration and immunocastration. Animal: An International Journal of Animal Bioscience 3: 1124-1132. doi:10.1017/S1751731109004510

Zamaratskaia G, Rasmussen MK, Škrlep M, Batorek Lukač N, Škorjanc D, Čandek-Potokar M (2015) Tissue-specific regulation of CYP3A by hydrolysable tannins in male pigs. Xenobiotica 2:1-6. doi:10.3109/00498254.2015.1099081

Zlabek V, Zamaratskaia G (2012) Comparison of three fluorescent CYP3A substrates in two vertebrate models: pig and Atlantic salmon. Animal 6(4):633-640. doi:10.1017/S1751731111002096 